\title{
System Dynamics Simulation of Large-Scale Generation System for Designing Wind Power Policy in China
}

\author{
Linna Hou ${ }^{1,2}$ \\ ${ }^{1}$ School of Management, Xian Jiaotong University, Xian, Shaanxi 710049, China \\ ${ }^{2}$ School of Economics and Management, Xi'an University of Technology, Xi'an, Shaanxi 710054, China \\ Correspondence should be addressed to Linna Hou; houlinnaie@163.com
}

Received 2 December 2014; Revised 17 January 2015; Accepted 17 January 2015

Academic Editor: Qingang Xiong

Copyright (C) 2015 Linna Hou. This is an open access article distributed under the Creative Commons Attribution License, which permits unrestricted use, distribution, and reproduction in any medium, provided the original work is properly cited.

\begin{abstract}
This paper focuses on the impacts of renewable energy policy on a large-scale power generation system, including thermal power, hydropower, and wind power generation. As one of the most important clean energy, wind energy has been rapidly developed in the world. But in recent years there is a serious waste of wind power equipment and investment in China leading to many problems in the industry from wind power planning to its integration. One way overcoming the difficulty is to analyze the influence of wind power policy on a generation system. This paper builds a system dynamics (SD) model of energy generation to simulate the results of wind energy generation policies based on a complex system. And scenario analysis method is used to compare the effectiveness and efficiency of these policies. The case study shows that the combinations of lower portfolio goal and higher benchmark price and those of higher portfolio goal and lower benchmark price have large differences in both effectiveness and efficiency. On the other hand, the combinations of uniformly lower or higher portfolio goal and benchmark price have similar efficiency, but different effectiveness. Finally, an optimal policy combination can be chosen on the basis of policy analysis in the large-scale power system.
\end{abstract}

\section{Introduction}

Limited mineral resources and increasing global environmental pressures underline the importance of renewable energy development for many countries [1]. China is gifted with abundant wind resources; the installed wind capacity has been increasing rapidly and reached $917 \mathrm{GW}$ in 2013.

Unlike in Europe where an interconnected system with geographically disperse wind farms has been proposed, China's wind energy can be characterized as centralized and large-scale development. Due to intermittency and volatility, it is difficult for wind power to be connected to the grid totally. There is a large proportion of installed capacity that cannot be integrated into the power grid. All of these result in a great number of equipment staying idle and causing significant investment loss. Even if it is connected, wind curtailment often happens for some reasons. The curtailment has reached 15 billion $\mathrm{kWh}$ in 2013 [2]. These have affected not only the waste of wind energy, but also the investors' expectations. Therefore, it is an important task to design reasonable policies for sustainable development of wind energy.
The policies on renewable energy (hereafter denoted as $\mathrm{RE}$ ) were evaluated by the three criteria of effectiveness, efficiency, and equity [3-5]. Jacobsson et al. [6] also pointed out that the three indexes should be considered when designing European Union RE support policy. Some RE policies were typically analyzed in terms of effectiveness and efficiency. Zhou et al. [7] designed incentive policies for RE generation, effectiveness was measured by the capability of achieving a goal for Renewable Portfolio Standard (hereafter denoted as RPS), and efficiency was measured by the amount of intervention, including collected taxes, paid subsidies, and increased cost resulting from generation expansion planning, while effectiveness was defined as saving energy and efficiency was explained as costs by Streimikiene et al. [8]. Furthermore, Mendonça et al. [9] considered that effectiveness and efficiency were not enough for evaluating the impacts of RE policies, and other factors, especially local acceptance, also influence RE development.

More studies only focused on effectiveness or efficiency. From the view of effectiveness, Carley [10] used the percentage of RE generation as an indicator and found RPS 
policy cannot promote the RE development significantly. Farooq et al. [11] compared the effects of various RPS targets on conventional and renewable energy generation capacity based on MARKAL framework. They thought that a higher RPS target can reduce fuel consumption, but, meanwhile, the generation cost also increased obviously. According to Bürer and Wüstenhagen [12], feed-in tariffs (FIT) were also thought as the most effective policy based on companies' investment interest. Cherni and Kentish [13] examined the potential effectiveness of the RE policy in China and found there were three major obstacles to its development including the high development cost, the difficulty for connecting to the grid, and the institutional barriers. From the view of efficiency, Fouquet and Johansson [14] found that FIT can make RE develop faster at a lower cost in comparison to tradable green certificates (TGC). And Sun and Nie [15] also came to the same conclusion by comparing R\&D input, market price, consumer surplus, and so on. Jenner et al. [16] considered the FIT policy can promote photovoltaic generation. Li et al. [17] discussed the influence of FIT on wind power operation management risk and they gave some strategies to improve China's wind power management. Dong [18] evaluated the effects of RPS and FIT on wind capacity by an empirical test and estimated FIT can increase the total capacity of wind power more than RPS.

Many researches showed that the policies have important roles in RE development; therefore the relationship between policies and development results need to be found out. $\mathrm{SD}$ is a good method to analyze a long-term change of variables, which is suitable for energy policy investigation. Ford [19] summarized the early applications and proved that SD was valuable for policy analysis for the government and power companies. Dyner et al. [20] applied SD to design gas penetration policies by calculating energy efficiency and energy savings under different scenarios. Hsu [21] assessed the effects of capital subsidies and FIT on solar PV installations in terms of a SD model to simulate the economic benefit of policy combination. Another SD model was used to evaluate an offshore wind-farm's effects on local ecology and social economy from the stakeholder's standpoint by Château et al. [22]. Aslani et al. [23] developed a SD model to simulate renewable energy generation on the basis of different scenarios policies in Finland. Sheikhi Fini et al. [24] applied SD method to discuss the policies' impacts on the expansion of wind resources, combined heat and power, and photovoltaic resources. Xiong et al. [25, 26] designed a GPU-based system and developed a combinational fast algorithm of discrete particle, which helped to enhance the simulation speed and improve the simulation efficiency of complex systems.

These studies analyzed the influence of policies on energy development and provided some suggestions for policy making. China has also proposed new energy development goals and policies; however, the issues should be discussed on the goal realization and the cost for achieving it, and the solution lies in expectation and evaluation for the results of policies. The purpose of this paper is to design effective and efficient policies for wind power development based on a complex generation system.

\section{Modeling and Analysis}

To analyze the effectiveness and efficiency of policies, the paper considers not only wind power but also thermal power and hydropower closely related to it. The whole system is made up of wind energy subsystem, conventional energy subsystem including thermal power and hydropower, and policy adjusting subsystem. These variables are explained in Table 1.

\section{A causal loop diagram is shown in Figure 1.}

In Figure 1, wind energy subsystem is described in the left dashed box. The conventional energy subsystem is in the right dash dot box. And the policy adjusting subsystem is in the middle box. Four main loops are explained as follows.

Loop (1) shows a causal relationship in wind energy subsystem.

Loop (1): wind energy generation (WEG) $\rightarrow$ income of wind energy production (IWEP) $\rightarrow$ profit rate of wind power (PRWP) $\rightarrow$ investment rate of wind energy capacity (IRWEC) $\rightarrow$ wind power system capacity (WPSC) $\rightarrow$ available wind energy generation (AWEG) $\rightarrow$ wind energy generation (WEG).

Loops (2) and (3) show the relationships between wind energy and hydropower in the conventional energy subsystem.

Loop (2): wind energy generation (WEG) $\rightarrow$ income of wind energy production (IWEP) $\rightarrow$ profit rate of wind power (PRWP) $\rightarrow$ investment rate of wind energy capacity (IRWEC) $\rightarrow$ wind power system capacity (WPSC) $\rightarrow$ system equivalent capacity (SEC) $\rightarrow$ capacity gap (CG) $\rightarrow$ capacity investment plan (CIP) $\rightarrow$ investment rate of hydropower capacity (IRHYC) $\rightarrow$ hydropower system capacity (HYSC) $\rightarrow$ hydropower generation $(\mathrm{HYG}) \rightarrow$ wind energy generation (WEG).

Loop (3): wind energy generation (WEG) $\rightarrow$ income of wind energy production (IWEP) $\rightarrow$ profit rate of wind power (PRWP) $\rightarrow$ investment rate of wind energy capacity (IRWEC) $\rightarrow$ wind power system capacity (WPSC) $\rightarrow$ system equivalent capacity (SEC) $\rightarrow$ capacity gap (CG) $\rightarrow$ capacity investment plan (CIP) $\rightarrow$ investment rate of hydropower capacity (IRHYC) $\rightarrow$ hydropower system capacity (HYSC) $\rightarrow$ hydropower generation (HYG) $\rightarrow$ calculated portfolio $(\mathrm{CP}) \rightarrow$ portfolio goal $(\mathrm{PG}) \rightarrow$ investment rate of wind energy capacity (IRWEC) $\rightarrow$ wind power system capacity (WPSC) $\rightarrow$ available wind energy generation $(\mathrm{AWEG}) \rightarrow$ wind energy generation (WEG).

Loop (4) expresses the relationship between wind energy and thermal power in the conventional energy subsystem.

Loop (4): wind energy generation (WEG) $\rightarrow$ income of wind energy production (IWEP) $\rightarrow$ profit rate of wind power (PRWP) $\rightarrow$ investment rate of wind energy capacity (IRWEC) $\rightarrow$ wind power system capacity (WPSC) $\rightarrow$ system equivalent capacity (SEC) $\rightarrow$ capacity gap (CG) $\rightarrow$ capacity investment plan (CIP) $\rightarrow$ investment rate of thermal power capacity (IRTHC) $\rightarrow$ thermal power system capacity $(\mathrm{THSC}) \rightarrow$ thermal power generation (THG) $\rightarrow$ calculated portfolio $(\mathrm{CP}) \rightarrow$ portfolio goal $(\mathrm{PG}) \rightarrow$ investment rate 


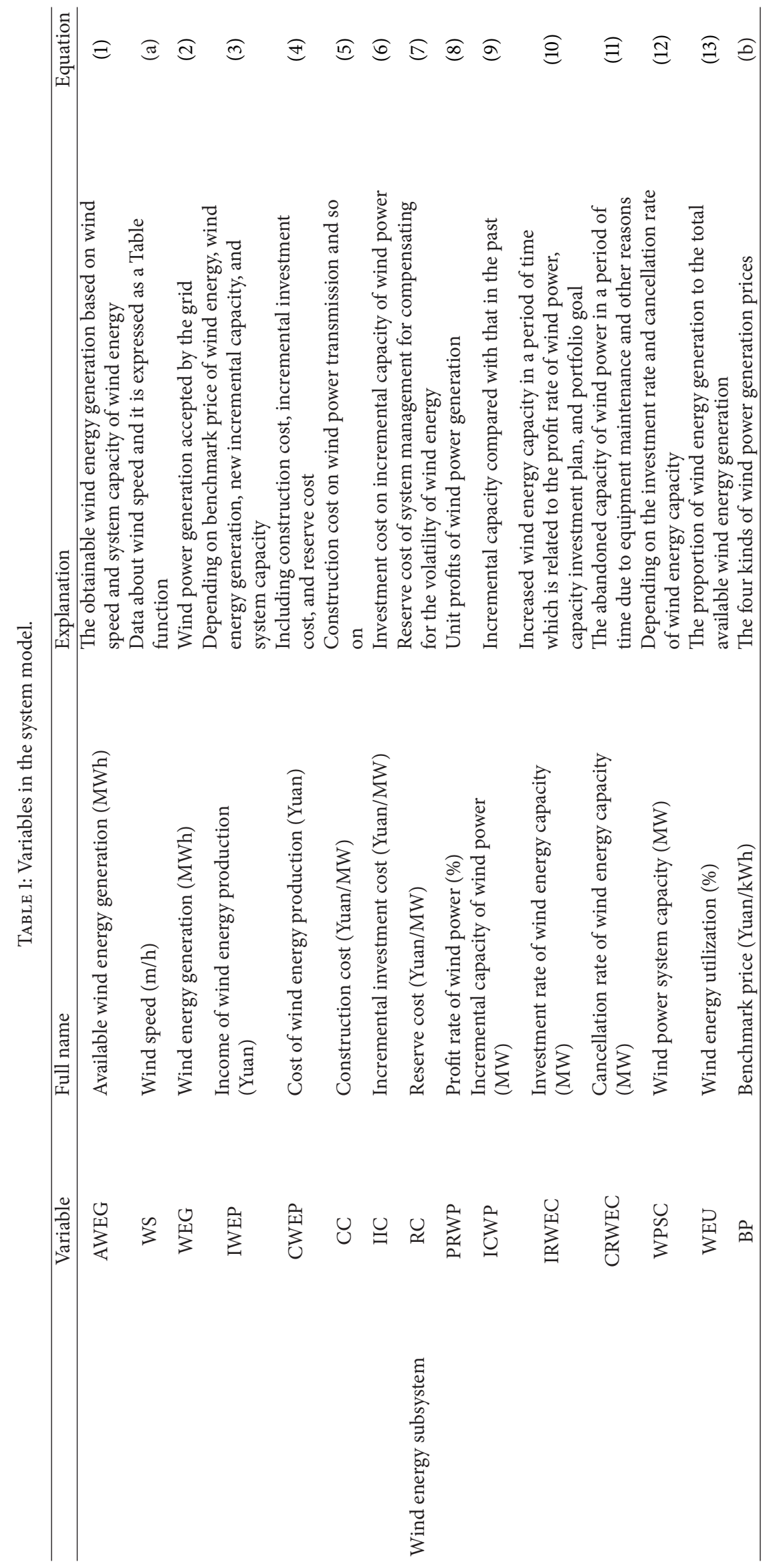




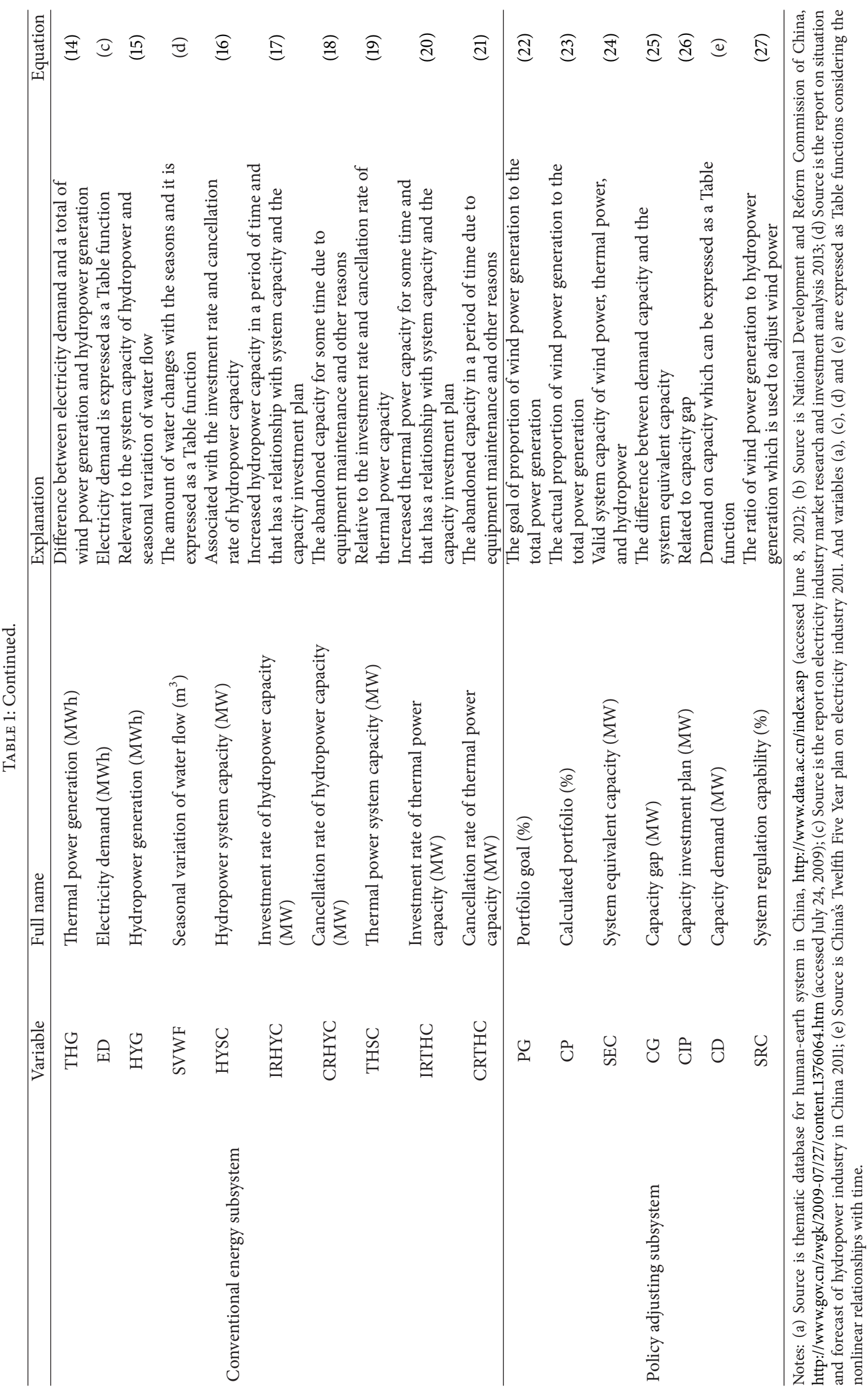




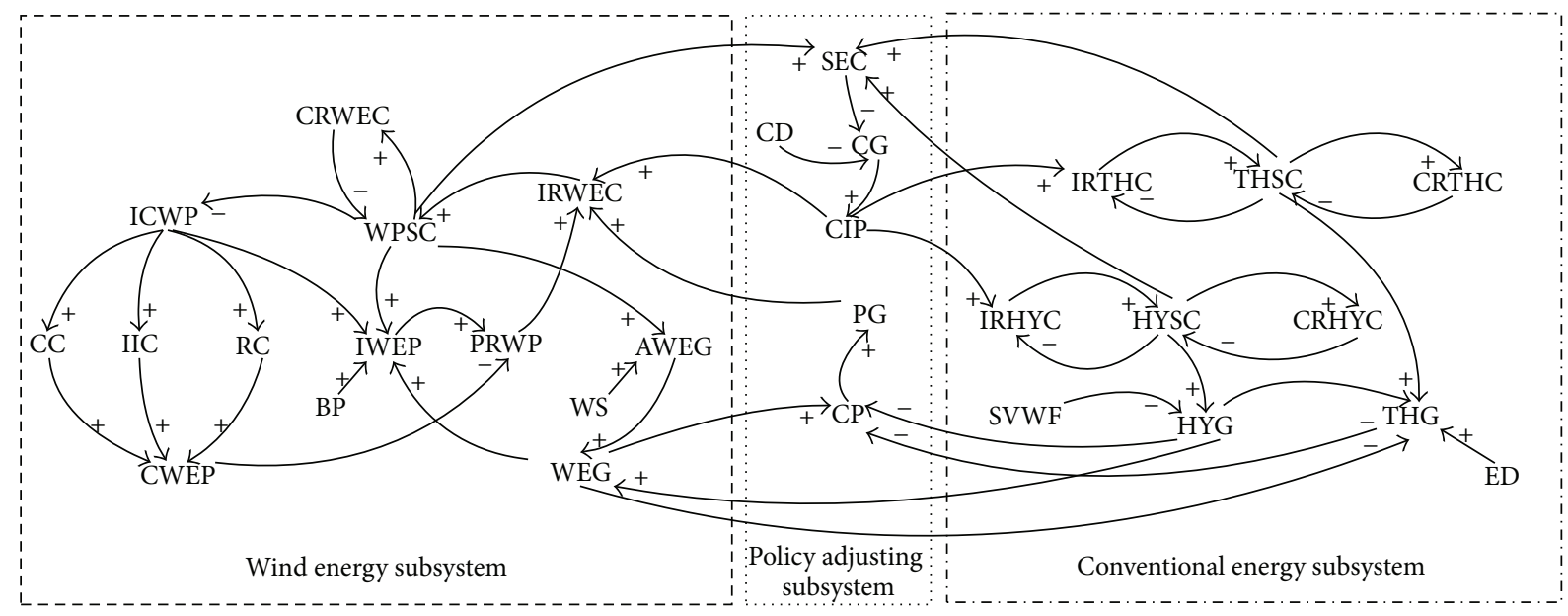

Figure 1: Causal loop diagram.

of wind energy capacity (IRWEC) $\rightarrow$ wind power system capacity (WPSC) $\rightarrow$ available wind energy generation $(\mathrm{AWEG}) \rightarrow$ wind energy generation (WEG). below.

The specific relationships between variables are given

2.1. Wind Energy Subsystem. In order to analyze policies of wind energy, wind energy subsystem is the backbone. This paper considers technical factors (such as wind energy output influenced by wind speed, installed capacity, and so on) and economic factors (such as the economy of investment decided by the profit rate).

2.1.1. The Technical Relationship of Wind Energy Generation. The available wind energy generation (AWEG) at time $t$ can be obtained by (1)

$$
\operatorname{AWEG}(t)= \begin{cases}0 & \text { if WS }(t)<v_{i} \quad \text { or } \quad \mathrm{WS}(t)>v_{o} \\ \operatorname{WPSC}(t) * d t & \text { if } v_{r}<\mathrm{WS}(t) \leq v_{o} \\ \frac{\mathrm{WPSC}(t) *\left(\mathrm{WS}(t)-v_{i}\right) * d t}{\left(v_{r}-v_{i}\right)} & \text { if } v_{i} \leq \mathrm{WS}(t) \leq v_{r},\end{cases}
$$

where $d t$ represents a period of time which started from $t, v_{i}$ is the cut-in speed, $v_{o}$ is the cut-out speed, and $v_{r}$ is the rated speed of wind turbines.

In this model, a Table function is used to describe the wind speed (WS) considering the nonlinear relationships with time and the dynamic behavior is expressed as follows.

A Table is presented as $\left(T_{1}, Y_{1}\right),\left(T_{2}, Y_{2}\right), \ldots,\left(T_{n}, Y_{n}\right)$ showing relations between time $T$ and variable $Y$; each element of a matrix is a value which can be accurately positioned by two variables. The same considerations also involve some variables including electricity demand (ED), seasonal variation of water flow (SVWF), and capacity demand (CD).

A certain proportion of hydropower is used to compensate for wind power because of its intermittency and volatility, as shown in (2)

$$
\begin{aligned}
& \operatorname{WEG}(t) \\
& =\underline{\operatorname{WEG}(t)}+\min \{(\operatorname{AWEG}(t)-\underline{\mathrm{WEG}(t)}), \alpha \mathrm{HYG}(t)\},
\end{aligned}
$$

where WEG $(t)$ is the lower limit of wind power and it is given by considering the comprehensive accommodation capability of wind power. $\alpha$ is a coefficient and $0 \leq \alpha<1$.

\subsubsection{Investment Economy Analysis of Wind Energy Genera-} tion. Investment in wind farms concerns the recent benefit particularly. Benchmark price (BP) of wind power is one of the important factors that influence the profit and investment. Different countries have various electricity price policies. In the early stage before 2009, a bidding price system used in China was similar to the Non-Fossil Fuel Obligation (NFFO) in Britain, but it brought many problems, such as a lower bidding price and ambiguous expected benefits. Drawing on the experience of the fixed price system in Germany, National Development and Reform Commission of China (hereafter denoted as NDRC) set benchmark prices for wind power ranging as follows: $0.51 \mathrm{Yuan} / \mathrm{kWh}, 0.54$ Yuan/kWh, 0.58 Yuan/kWh, and 0.61 Yuan/kWh. The economic analysis on investment is based on (3)-(12):

$$
\operatorname{IWEP}(t)=\frac{\operatorname{ICWP}(t)}{\operatorname{WPSC}(t)} * \mathrm{BP}(t) * \operatorname{WEG}(t),
$$




$$
\begin{gathered}
\operatorname{CWEP}(t)=\operatorname{CC}(t)+\operatorname{IIC}(t)+\operatorname{RC}(t), \\
\operatorname{CC}(t)=\theta_{1} * \operatorname{ICWP}(t), \\
\operatorname{IIC}(t)=\theta_{2} * \operatorname{ICWP}(t), \\
\operatorname{RC}(t)=\theta_{3} * \operatorname{ICWP}(t), \\
\operatorname{PRWP}(t)=\frac{\operatorname{IWEP}(t)-\operatorname{CWEP}(t)}{\operatorname{CWEP}(t)}, \\
\operatorname{ICWP}(t)=\operatorname{WPSC}(t)-\operatorname{WPSC}(t-1) .
\end{gathered}
$$

If the profit rate is less than 0 , the investment also happens because of a mandatory policy RPS:

$$
\begin{aligned}
& \operatorname{IRWEC}(t) \\
& = \begin{cases}(1+\operatorname{PRWR}(t)) * \operatorname{PG}(t) * \operatorname{CIP}(t) & \text { if } \operatorname{PRWP}(t)>0 \\
\operatorname{PG}(t) * \operatorname{CIP}(t) & \text { if } \operatorname{PRWP}(t) \leq 0\end{cases} \\
& \operatorname{CRWEC}(t)=\theta_{4} * \operatorname{WPSC}(t), \\
& \operatorname{WPSC}(t)=\operatorname{WPSC}(0)+\sum_{t=1}^{t} \operatorname{IRWEC}(t)-\operatorname{CRWEC}(t),
\end{aligned}
$$

where $\theta_{1}, \theta_{2}$, and $\theta_{3}$ are constants based on the data from investment and construction project on wind farm. $\theta_{4}$ can be estimated from the maintenance plan and the life cycle of wind turbines.

2.1.3. Wind Energy Utilization (WEU). WEU in (13) indicates the percentage of wind energy generation to the total available wind energy generation, which reflects the ratio of wind power accepted by the grid:

$$
\mathrm{WEU}=\frac{\sum_{t=0}^{\text {Endtime }} \operatorname{WEG}(t)}{\sum_{t=0}^{\text {Endtime }} \operatorname{AWEG}(t)} * 100 \% .
$$

2.2. Conventional Energy Subsystem. The conventional energy subsystem consists of hydropower and thermal power. One basic concept is discussed here.

Power system operation requires the real-time balance between supply and demand. In this paper, wind and water, as renewable energy, are assumed to generate electricity as much as possible under technical constraints. Thermal power can be utilized to meet the rest of the demand. As a result, the relationship is defined as

$$
\begin{aligned}
& \operatorname{THG}(t) \\
& =\min \{\operatorname{THSC}(t) * d t, \operatorname{ED}(t)-\operatorname{HYG}(t)-\operatorname{WEG}(t)\} .
\end{aligned}
$$

In (14), HYG $(t)$ is the hydropower generation which can be predicted by long-term forecasting methods [27], and that is evaluated based on the statistics of the seasonal changes of water flow $\operatorname{SVWF}(t)$, as shown in

$$
\operatorname{HYG}(t)=\operatorname{SVWF}(t) * \operatorname{HYSC}(t) .
$$

The relationships between system capacity, investment rate, and cancellation rate of hydropower as well as thermal power are given as

$$
\begin{gathered}
\operatorname{HYSC}(t)=\operatorname{HYSC}(0)+\sum_{t=1}^{t} \operatorname{IRHYC}(t)-\operatorname{CRHYC}(t), \\
\operatorname{IRHYC}(t)=\delta_{1} * \operatorname{CIP}(t), \\
\operatorname{CRHYC}(t)=\delta_{2} * \operatorname{HYSC}(t), \\
\operatorname{THSC}(t)=\operatorname{THSC}(0)+\sum_{t=1}^{t} \operatorname{IRTHC}(t)-\operatorname{CRTHC}(t), \\
\operatorname{IRTHC}(t)=\delta_{3} * \operatorname{CIP}(t), \\
\operatorname{CRTHC}(t)=\delta_{4} * \operatorname{THSC}(t),
\end{gathered}
$$

where $\delta_{1}, \delta_{2}, \delta_{3}$, and $\delta_{4}$ are constants.

2.3. Policy Adjusting Subsystem. Two important concepts are analyzed here.

2.3.1. Portfolio Goal (PG). For promoting renewable energy development, not only the incentive policy (benchmark price), but also the obliged policy is necessary. RPS is a valid policy in many countries that places an obligation role to accept a specified proportion of energy generation from renewable sources. Most states in the United States, Japan, Australia, and many other developed countries and regions have implemented RPS. Standards for RE portfolio are discussed in China now, but there is no specific implementation route. Related calculations are presented in (22)-(26):

$$
\begin{gathered}
\mathrm{PG}(t)=\min \{\mathrm{CP}(t), \underline{\mathrm{PG}}\} \\
\mathrm{CP}(t)=\frac{\mathrm{WEG}(t)}{(\mathrm{WEG}(t)+\operatorname{HYG}(t)+\operatorname{THG}(t))}, \\
\mathrm{SEC}(t)=\eta_{1} * \operatorname{THSC}(t)+\eta_{2} * \operatorname{HYSC}(t)+\eta_{3} * \operatorname{WPSC}(t),
\end{gathered}
$$

where $\mathrm{PG}$ in (22) represents the lower limit of the target reflecting RPS policy, that is, a mandatory proportion of wind power generation to the total generation. $\mathrm{CP}(t)$ in $(22)$ and (23) denotes the actual percentage of wind power generation. $\eta_{1}, \eta_{2}$, and $\eta_{3}$ in (24) are validity coefficients of thermal power capacity, hydropower capacity, and wind power capacity, respectively:

$$
\begin{aligned}
& \mathrm{CG}(t)=\operatorname{CD}(t)-\operatorname{SEC}(t), \\
& \operatorname{CIP}(t)=\max \{\operatorname{CG}(t), 0\} .
\end{aligned}
$$


TABLE 2: Evaluation indexes in related literature.

\begin{tabular}{|c|c|c|c|}
\hline & Evaluation object & Effectiveness & Efficiency \\
\hline Yuan et al. (2014) [28] & $\begin{array}{l}\text { Investment policy for } \\
\text { China's PV industry }\end{array}$ & PV production capacity & $\begin{array}{l}\text { Average price of } \mathrm{PV} \\
\text { modules }\end{array}$ \\
\hline Verbruggen (2009) [3] & $\begin{array}{l}\text { RES-E support system in } \\
\text { Flanders }\end{array}$ & Measurement of goal realization & $\begin{array}{l}\text { The proportion of useful } \\
\text { outputs to inputs }\end{array}$ \\
\hline Starkey (2012) [5] & Personal carbon trading & $\begin{array}{l}\text { Whether or not to complete the } \\
\text { required target }\end{array}$ & The cost for achieving goals \\
\hline $\begin{array}{l}\text { Jacobsson et al. (2009) } \\
\text { [6] }\end{array}$ & $\begin{array}{l}\text { EU renewable energy } \\
\text { support policy }\end{array}$ & $\begin{array}{l}\text { Innovation and industrialization } \\
\text { of RES-E technology }\end{array}$ & \\
\hline Zhou et al. (2011) [7] & $\begin{array}{l}\text { Renewable energy incentive } \\
\text { policy }\end{array}$ & $\begin{array}{l}\text { The ability to complete renewable } \\
\text { portfolio standards }\end{array}$ & $\begin{array}{l}\text { The amount of policy } \\
\text { intervention }\end{array}$ \\
\hline $\begin{array}{l}\text { Streimikiene et al. (2012) } \\
\text { [8] }\end{array}$ & $\begin{array}{l}\text { Energy use efficiency in } \\
\text { Lithuania }\end{array}$ & The amount of energy saving & $\begin{array}{l}\text { Achieved energy saving for } \\
\text { one unit of cost }\end{array}$ \\
\hline Carley (2009) [10] & RPS in the United States & $\begin{array}{l}\text { The amount of renewable energy } \\
\text { generation and its percentage }\end{array}$ & \\
\hline $\begin{array}{l}\text { Bürer and Wüstenhagen } \\
\text { (2009) [12] }\end{array}$ & Renewable energy policies & $\begin{array}{l}\text { The interest of private investors } \\
\text { in clean energy technologies }\end{array}$ & \\
\hline $\begin{array}{l}\text { Cherni and Kentish } \\
\text { (2007) [13] }\end{array}$ & $\begin{array}{l}\text { Renewable energy policies } \\
\text { in China }\end{array}$ & $\begin{array}{l}\text { The potential effectiveness is } \\
\text { examined by predicting } \\
\text { renewable energy capacity and } \\
\text { demand }\end{array}$ & \\
\hline
\end{tabular}

2.3.2. System Regulation Capability (SRC). Part of hydropower $\alpha \mathrm{HYG}(t)$ is used to compensate for the volatility of wind power; SRC is defined as

$$
\mathrm{SRC}=\frac{\sum_{t=0}^{\text {Endtime }} \operatorname{WEG}(t)}{\sum_{t=0}^{\text {Endtime }} \alpha \operatorname{HYG}(t)} * 100 \% .
$$

2.4. Stock and Flow Diagram. Stock and flow diagram is shown in Figure 2.

The input parameters and evaluation indexes are introduced.

2.4.1. Input Parameters. Main input parameters include wind speed (WS), electricity demand (ED), seasonal variation of water flow (SVWF), and capacity demand (CD). In addition, the portfolio goal (PG) and benchmark price (BP) are also the important input parameters. With their different values, various policy combination scenarios can be constructed to simulate the policies' effectiveness and efficiency. Based on these results, an optimal policy combination can be obtained.

2.4.2. Evaluation Indexes. Table 2 briefly summarizes relevant research results on the effectiveness or efficiency of renewable energy policies.

This paper evaluates renewable energy policies in terms of effectiveness and efficiency. Effectiveness is estimated based on the policy target. China tries to support wind energy generation by RPS policy in future; as a result, its generation and a proportion to the total generation are considered; that is, WEG and CP are the two indicators for measuring the effectiveness. Efficiency is judged in terms of the expense for achieving goals; the compensation generation supported by hydropower should be taken into account. Therefore, two indicators of wind energy utilization (WEU) and system regulation capability (SRC) are chosen for evaluating the efficiency of policies.

\section{Results and Discussion}

A region of one province in China is selected which has largescale wind farms with $6.19 \mathrm{GW}$ capacity. At the same time, this region has rich hydropower resources which are used to adjust wind power fluctuation. In this model, monthly data is utilized and the simulation time horizon is five consecutive years starting from the current year.

3.1. Policy Combinations and the Results. The policy combinations refer to the combination of portfolio goal and benchmark price. The former is associated with RPS being discussed now in China and will be carried out in the near future. And the latter has been implemented since 2009 . According to the draft of assessment methods on RPS in 2014 , the reasonable portfolio goal ranges from $6 \%$ to $10 \%$ in the next five years. Benchmark price is 0.51 Yuan/kWh in the selected region; in order to describe its uncertainty, three types of benchmark price are used to simulate the variation: decreased price, unchangeable price, and increased price. Consequently, there are 15 combinations as shown in Table 3.

Figures 3 and 4 show the effectiveness and efficiency of policy combinations, respectively.

In Figure 3, the calculated portfolio is lower than portfolio goal from Combination $\mathrm{J}$ to Combination $\mathrm{O}$, and the gap becomes larger especially from Combination $\mathrm{M}$. When the goal is lower than $9 \%$ (before Combination I), calculated portfolio can reach or even exceed it. The excess is more when the goal is lower, but wind energy generation is also less. While Combinations $\mathrm{G}, \mathrm{H}$, and I are found which can achieve 


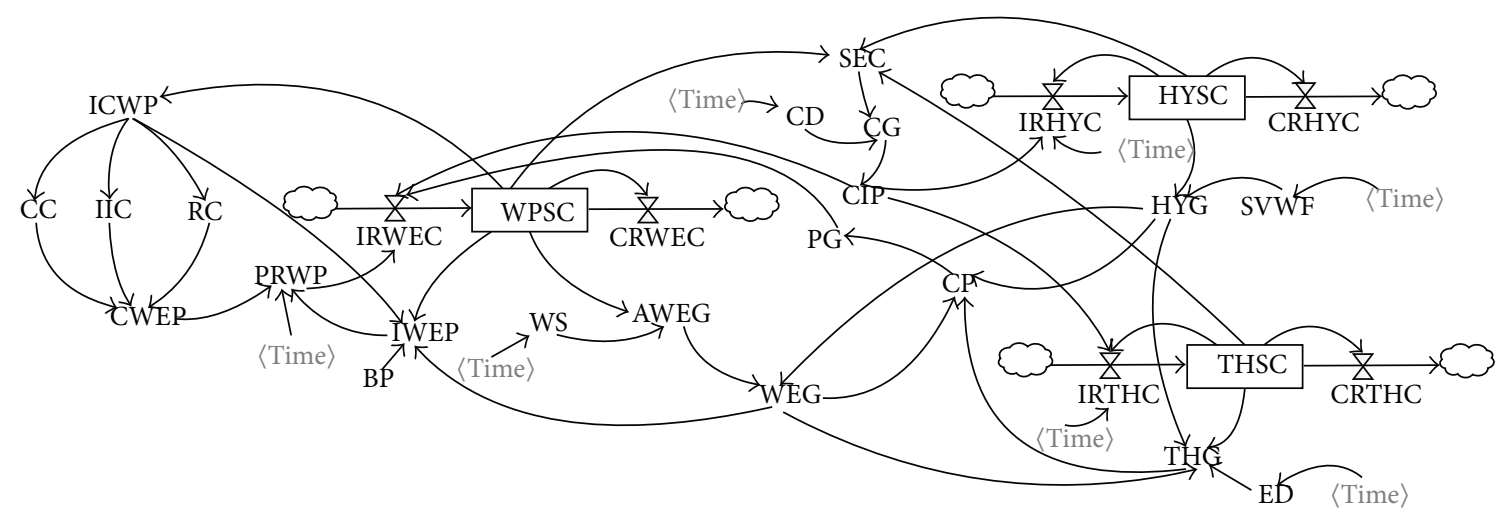

FIGURE 2: Stock and flow diagram.

TABle 3: Policy combinations.

\begin{tabular}{lccc}
\hline Policy combination & $\begin{array}{c}\text { Portfolio goal (\%); } \\
\text { benchmark price } \\
(\text { Yuan/kWh) }\end{array}$ & $\begin{array}{c}\text { Policy combination } \\
\begin{array}{c}\text { Portfolio goal (\%); } \\
\text { benchmark price } \\
(\text { Yuan/kWh) }\end{array}\end{array}$ & $\begin{array}{c}8 ; 0.54 \\
\text { A }\end{array}$ \\
B & $6 ; 0.48$ & I & $9 ; 0.48$ \\
C & $6 ; 0.51$ & J & $9 ; 0.51$ \\
D & $6 ; 0.54$ & L & $9 ; 0.54$ \\
E & $7 ; 0.48$ & M & $10 ; 0.48$ \\
F & $7 ; 0.51$ & N & $10 ; 0.51$ \\
G & $7 ; 0.54$ & O & $10 ; 0.54$ \\
H & $8 ; 0.48$ & & \\
\hline
\end{tabular}

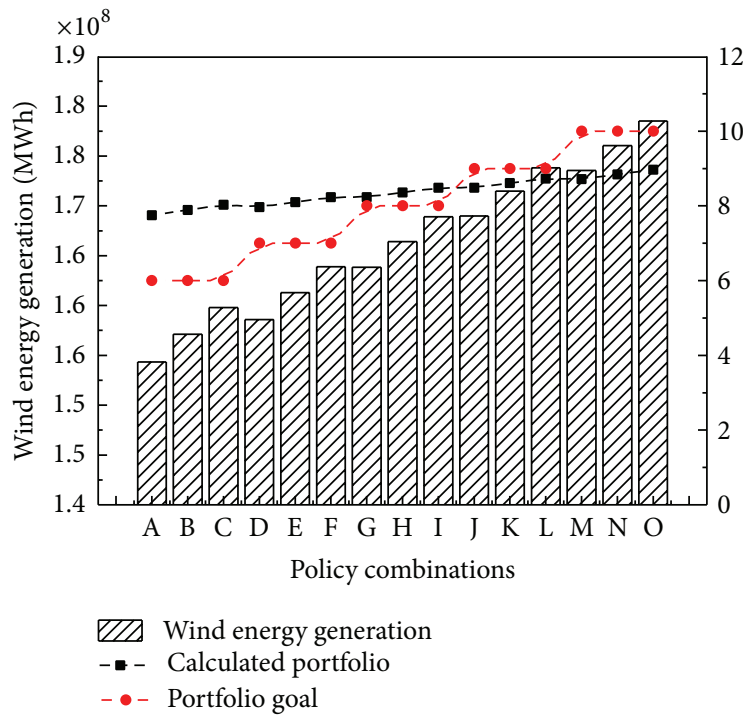

Figure 3: The wind energy generation, calculated portfolio, and portfolio goal of each policy combination.

the goal and have more wind energy generation, therefore, they are chosen as effective policies which means reasonable portfolio goal can be set as $8 \%$ for the five years in the future.

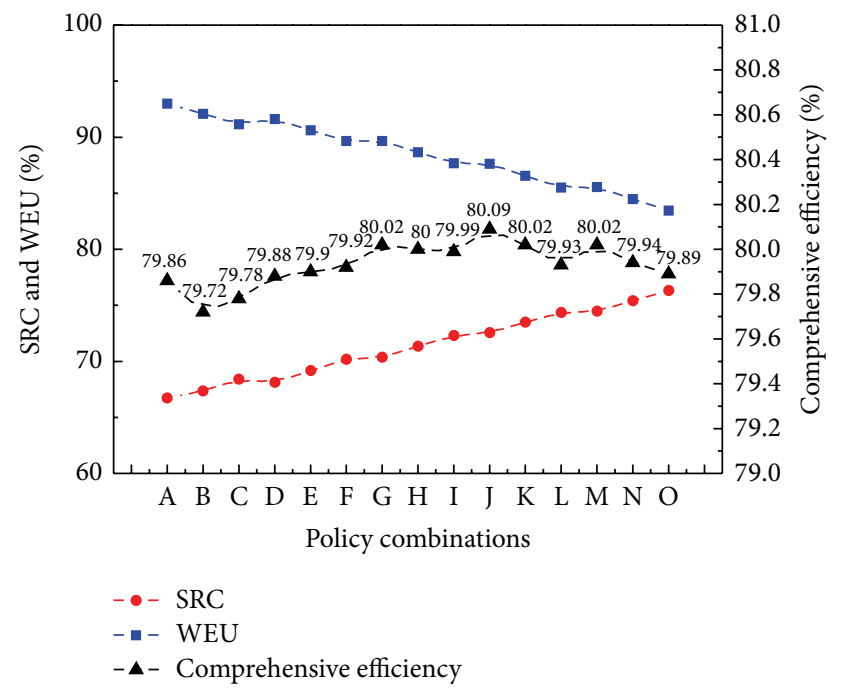

FIgURE 4: The comprehensive efficiency of each policy combination.

The focus here is on wind power; if considering photovoltaics, the ratio can be even higher.

Comprehensive efficiency is expressed by the mean value of two indexes, namely, SRC and WEU. It should be noted that although the values of comprehensive efficiency have no large gaps, the higher efficiency should be considered 


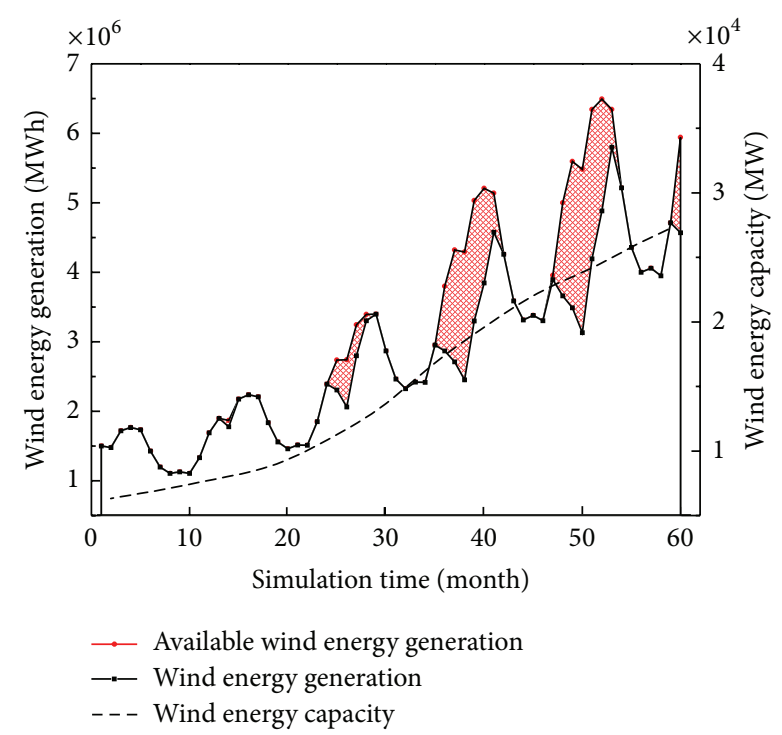

Figure 5: Multivariable trend chart of the optimal policy combination (Combination $\mathrm{H}$ ).

in order to promote the utilization of wind energy. From Figure 4, Combination $J$ has the highest efficiency, but it cannot reach the portfolio goal of $9 \%$ (Figure 3). Therefore, a choice should be made from Combinations $\mathrm{G}, \mathrm{H}$, and I. Among the three policy combinations, Combination G has the highest efficiency, but the minimum wind energy generation. Combination I has the lowest efficiency. As a result, Combination $\mathrm{H}$ is the optimal policy, which means that benchmark price should be set as 0.51 Yuan $/ \mathrm{kWh}$.

\subsection{The Simulation Results for the Optimal Policy Combina-} tion. Figures 5-7 display the simulation results of the optimal policy combination (Combination $\mathrm{H}$ ).

The shaded area in Figure 5 represents the curtailed wind energy caused by the difference between available wind energy generation and actual generation. With the rapid increase of wind power capacity, wind energy generation is more influenced by adjustable ability of hydropower generators, and that means part of wind power generation must be curtailed to keep the system in balance when the hydropower is not sufficient. The amount of curtailed generation increases quickly especially in the last two years. In Figure 5, both wind energy generation and available wind energy generation increase during the simulation period. While wind energy capacity increases steadily in the first two years, it then rises rapidly from the third year. The trend is close to an S-shaped growth curve.

The utilization hours refer to monthly valid number of hours for wind power, which is equal to its generation divided by the system capacity. The variable "the percentage of utilization hours" is chosen to illustrate the ratio of effective number of hours to the total hours, as the histogram in Figure 6.

The average percentage for each year is, respectively, $28.46 \%, 28.33 \%, 26.26 \%, 23.44 \%$, and $23.68 \%$. It reduces

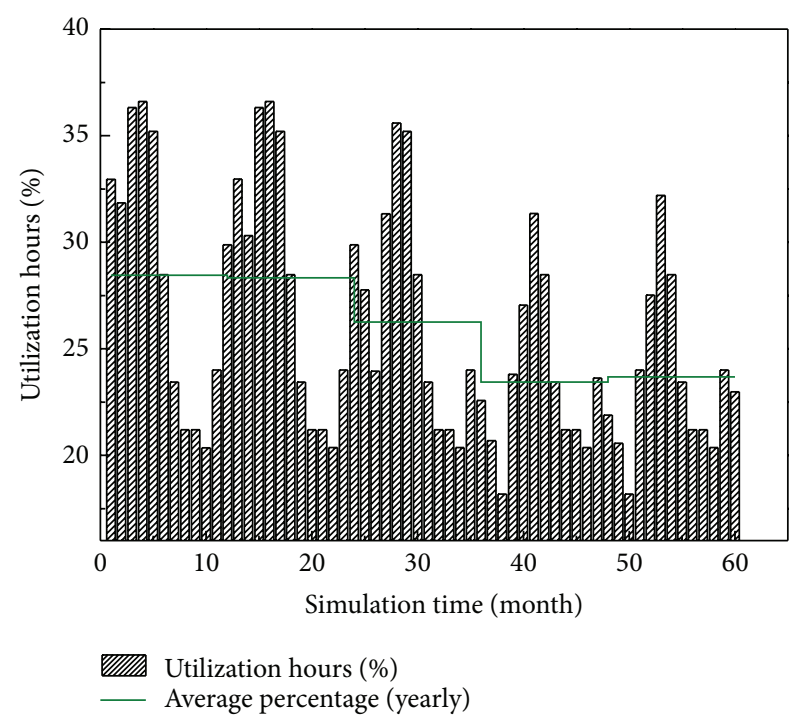

FIGURE 6: The percentage of utilization hours of wind energy generation.

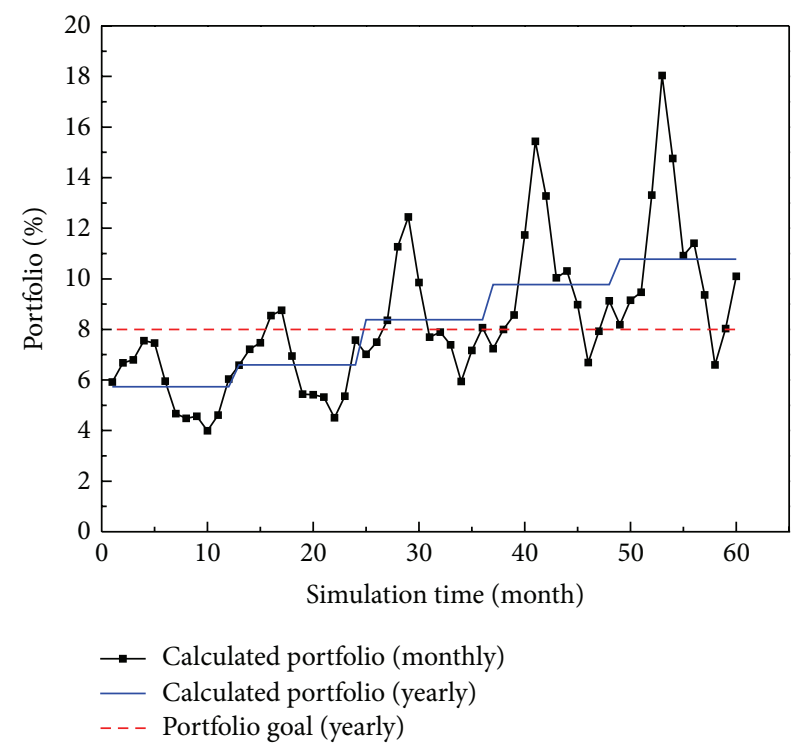

Figure 7: The relationship between calculated portfolio and portfolio goal.

gradually under the double impacts of RPS and benchmark price. RPS forces a certain percentage of wind power to be connected to the grid and benchmark price policy promotes the investment of wind energy generation. Based on the above two points, wind power capacity expands continuously while wind energy generation cannot increase concomitantly due to the limitation with hydropower; consequently, the average percentage declines.

Figure 7 displays a large fluctuation of the monthly calculated portfolio, particularly during the last two years because of the increased wind energy generation. Till the second year (before 24 months), the portfolio goal is realized only in two months. Starting from the third year, the number 
of months increases quickly that can accomplish the goal. The average portfolio for each year is $5.7 \%, 6.6 \%, 8.4 \%, 9.8 \%$, and $10.8 \%$. In the last three years, calculated portfolio is more than $8 \%$ and its average value for the five years is $8.25 \%$ that can achieve the predetermined goal of $8 \%$.

\section{Conclusion}

This paper establishes a system dynamics model of energy generation to simulate the results of wind power policy based on a complex system and discusses the influence of RPS and the benchmark price on the development of wind energy from the views of effectiveness and efficiency. As a result, an optimal policy combination can be obtained on the basis of scenario analysis.

The main conclusions can be summarized as follows. The combinations of lower portfolio goal and lower benchmark price and those of higher portfolio goal and higher benchmark price have similar efficiency, but the effectiveness varies greatly (as shown in Combinations $\mathrm{A}$ and $\mathrm{O}$ ). The combinations of lower portfolio goal and higher benchmark price and those of higher portfolio goal and lower benchmark price have large differences in both effectiveness and efficiency (as shown in Combinations $\mathrm{C}$ and $\mathrm{M}$ ). In this case, the combination of portfolio goal of $8 \%$ and benchmark price of 0.51 Yuan $/ \mathrm{kWh}$ is a suitable policy combination.

This paper provides an analysis method and gives some suggestions on wind power policy in China. In the future work, other types of renewable energy will be investigated.

\section{Conflict of Interests}

The author declares that there is no conflict of interests regarding the publication of this paper.

\section{Acknowledgment}

This work was supported by the National Natural Science Foundation of China (no. 71372164).

\section{References}

[1] J. You, "China's challenge for decarbonized growth: forecasts from energy demand models," Journal of Policy Modeling, vol. 35, no. 4, pp. 652-668, 2013.

[2] China State Electricity Regulatory Commission (CSERC), "Regulatory report on wind power generation and photovoltaic power generation," Tech. Rep., CSERC, 2013.

[3] A. Verbruggen, "Performance evaluation of renewable energy support policies, applied on Flanders' tradable certificates system," Energy Policy, vol. 37, no. 4, pp. 1385-1394, 2009.

[4] R. Starkey, "Personal carbon trading: a critical survey Part 1: equity," Ecological Economics, vol. 73, no. 15, pp. 7-18, 2012.

[5] R. Starkey, "Personal carbon trading: a critical survey part 2: efficiency and effectiveness," Ecological Economics, vol. 73, no. 15, pp. 19-28, 2012.

[6] S. Jacobsson, A. Bergek, D. Finon et al., "EU renewable energy support policy: faith or facts?” Energy Policy, vol. 37, no. 6, pp. 2143-2146, 2009.
[7] Y. Zhou, L. Wang, and J. D. McCalley, "Designing effective and efficient incentive policies for renewable energy in generation expansion planning," Applied Energy, vol. 88, no. 6, pp. 22012209, 2011.

[8] D. Streimikiene, A. Volochovic, and Z. Simanaviciene, "Comparative assessment of policies targeting energy use efficiency in Lithuania," Renewable and Sustainable Energy Reviews, vol. 16, no. 6, pp. 3613-3620, 2012.

[9] M. Mendonça, S. Lacey, and F. Hvelplund, "Stability, participation and transparency in renewable energy policy: lessons from Denmark and the United States," Policy and Society, vol. 27, no. 4, pp. 379-398, 2009.

[10] S. Carley, "State renewable energy electricity policies: an empirical evaluation of effectiveness," Energy Policy, vol. 37, no. 8, pp. 3071-3081, 2009.

[11] M. K. Farooq, S. Kumar, and R. M. Shrestha, "Energy, environmental and economic effects of renewable portfolio standards (RPS) in a developing country," Energy Policy, vol. 62, no. 1, pp. 989-1001, 2013.

[12] M. J. Bürer and R. Wüstenhagen, "Which renewable energy policy is a venture capitalist's best friend? Empirical evidence from a survey of international cleantech investors," Energy Policy, vol. 37, no. 12, pp. 4997-5006, 2009.

[13] J. A. Cherni and J. Kentish, "Renewable energy policy and electricity market reforms in China," Energy Policy, vol. 35, no. 7, pp. 3616-3629, 2007.

[14] D. Fouquet and T. B. Johansson, "European renewable energy policy at crossroads-focus on electricity support mechanisms," Energy Policy, vol. 36, no. 11, pp. 4079-4092, 2008.

[15] P. Sun and P. Nie, "A comparative study of feed-in tariff and renewable portfolio standard policy in renewable energy industry," Renewable Energy, vol. 74, pp. 255-262, 2015.

[16] S. Jenner, F. Groba, and J. Indvik, "Assessing the strength and effectiveness of renewable electricity feed-in tariffs in European Union countries," Energy Policy, vol. 52, pp. 385-401, 2013.

[17] C. Li, P. Li, and X. Feng, "Analysis of wind power generation operation management risk in China," Renewable Energy, vol. 64, no. 1, pp. 266-275, 2014.

[18] C. G. Dong, "Feed-in tariff vs. renewable portfolio standard: an empirical test of their relative effectiveness in promoting wind capacity development," Energy Policy, vol. 42, no. 1, pp. 476-485, 2012.

[19] A. Ford, "System dynamics and the electric power industry," System Dynamics Review, vol. 13, no. 1, pp. 57-85, 1997.

[20] I. Dyner, R. A. Smith, and G. E. Peña, "System dynamics modelling for residential energy efficiency analysis and management," Journal of the Operational Research Society, vol. 46, no. 10, pp. 1163-1173, 1995.

[21] C. W. Hsu, "Using a system dynamics model to assess the effects of capital subsidies and feed-in tariffs on solar PV installations," Applied Energy, vol. 100, pp. 205-217, 2012.

[22] P. A. Château, Y. C. Chang, H. Chen, and T. T. Ko, "Building a stakeholder's vision of an offshore wind-farm project: a group modeling approach," Science of the Total Environment, vol. 420, no. 15, pp. 43-53, 2012.

[23] A. Aslani, P. Helo, and M. Naaranoja, "Role of renewable energy policies in energy dependency in Finland: system dynamics approach," Applied Energy, vol. 113, pp. 758-765, 2014.

[24] A. Sheikhi Fini, M. Parsa Moghaddam, and M. K. Sheikh-ElEslami, "A dynamic model for distributed energy resource expansion planning considering multi-resource support 
schemes," International Journal of Electrical Power and Energy Systems, vol. 60, pp. 357-366, 2014.

[25] Q. Xiong, B. Li, F. Chen, J. Ma, W. Ge, and J. Li, "Direct numerical simulation of sub-grid structures in gas-solid flowGPU implementation of macro-scale pseudo-particle modeling," Chemical Engineering Science, vol. 65, no. 19, pp. 53565365, 2010.

[26] Q. Xiong, E. Madadi-Kandjani, and G. Lorenzini, "A LBMDEM solver for fast discrete particle simulation of particle-fluid flows," Continuum Mechanics and Thermodynamics, vol. 26, no. 6, pp. 907-917, 2014.

[27] S. Wang, L. Yu, L. Tang, and S. Wang, "A novel seasonal decomposition based least squares support vector regression ensemble learning approach for hydropower consumption forecasting in China," Energy, vol. 36, no. 11, pp. 6542-6554, 2011.

[28] C. Yuan, S. Liu, Y. Yang, D. Chen, Z. Fang, and L. Shui, "An analysis on investment policy effect of China's photovoltaic industry based on feedback model," Applied Energy, vol. 135, no. 1, pp. 423-428, 2014. 


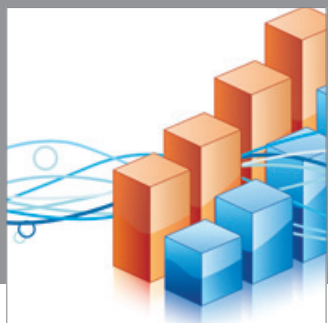

Advances in

Operations Research

mansans

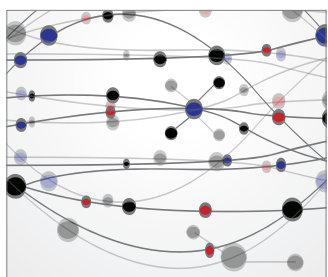

The Scientific World Journal
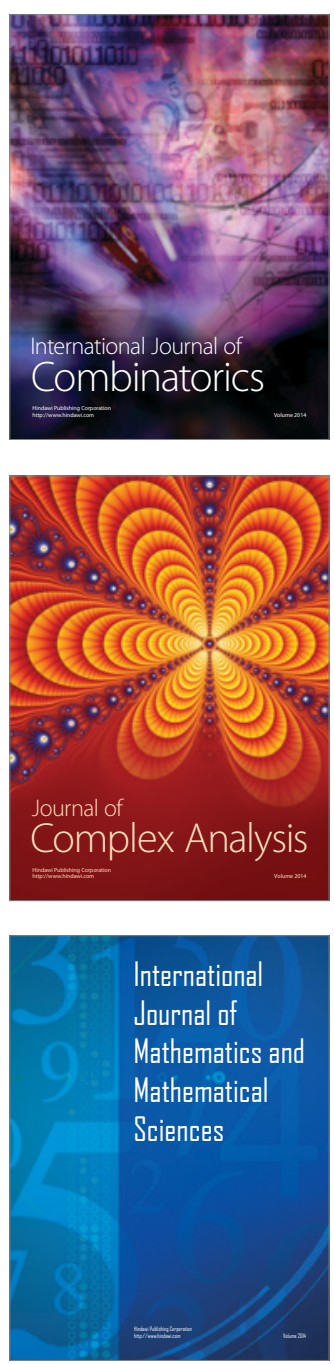
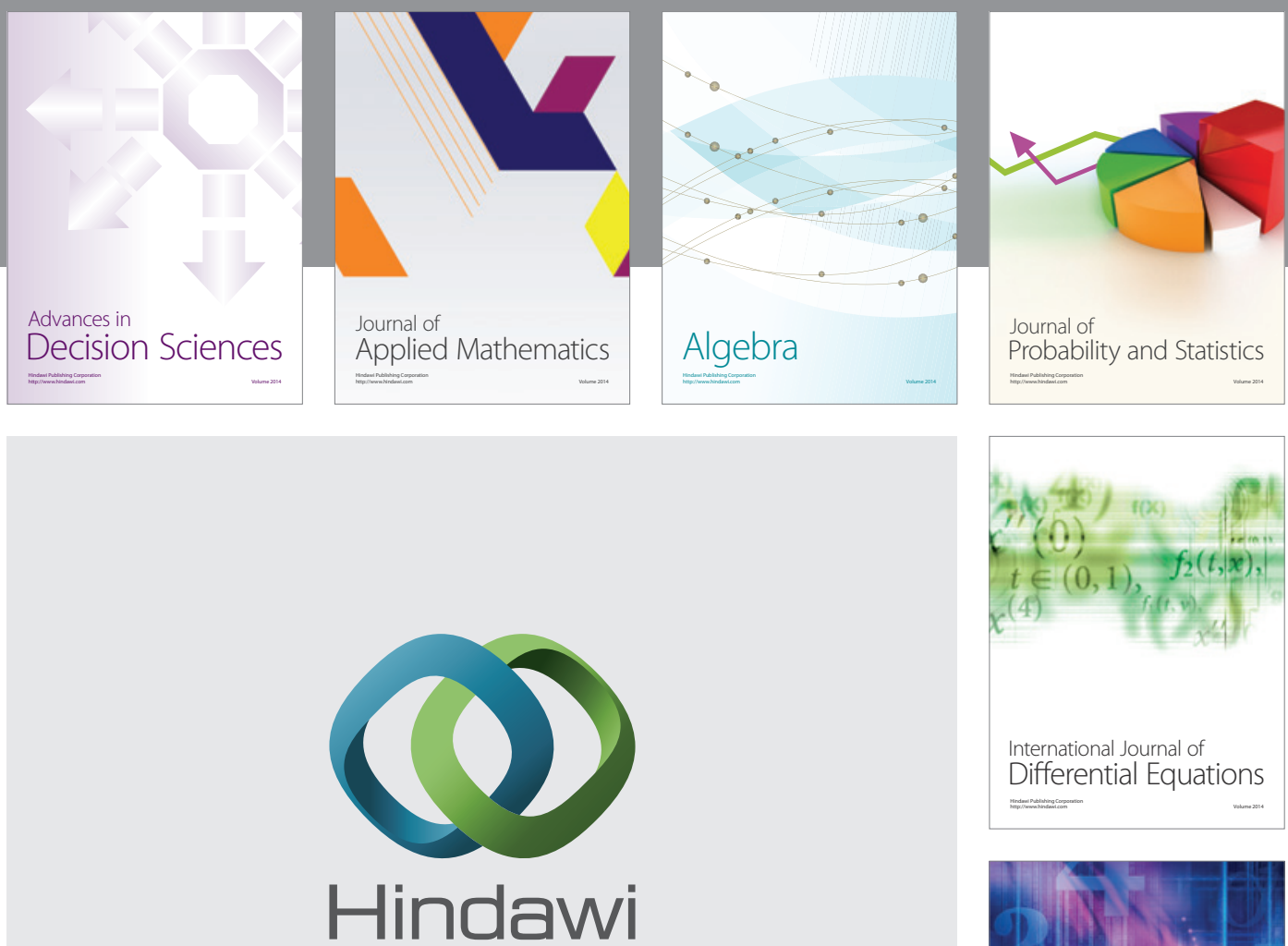

Submit your manuscripts at http://www.hindawi.com
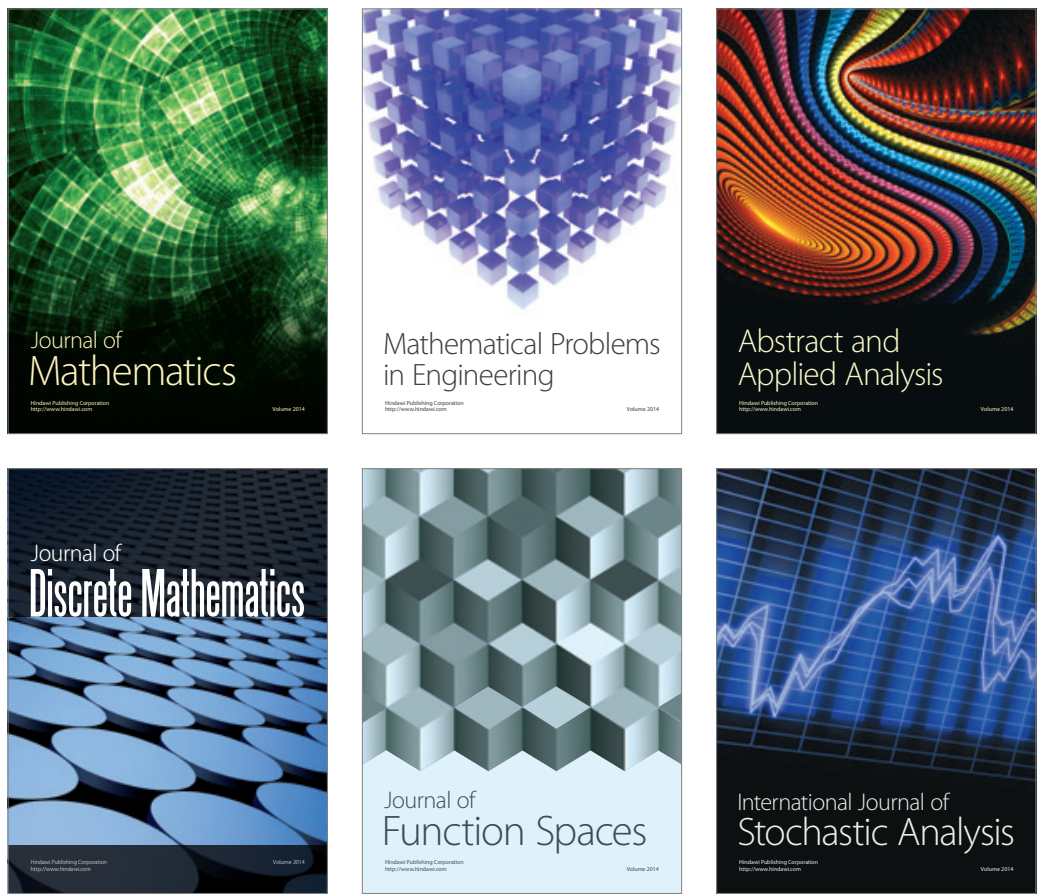

Journal of

Function Spaces

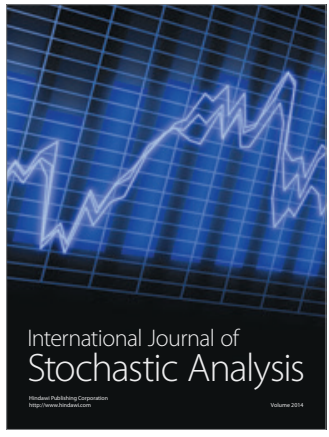

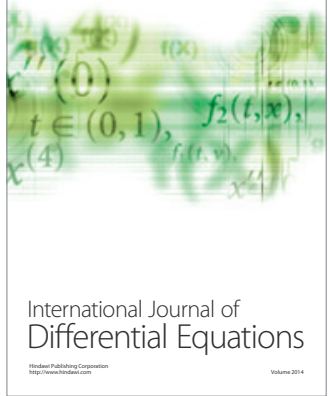
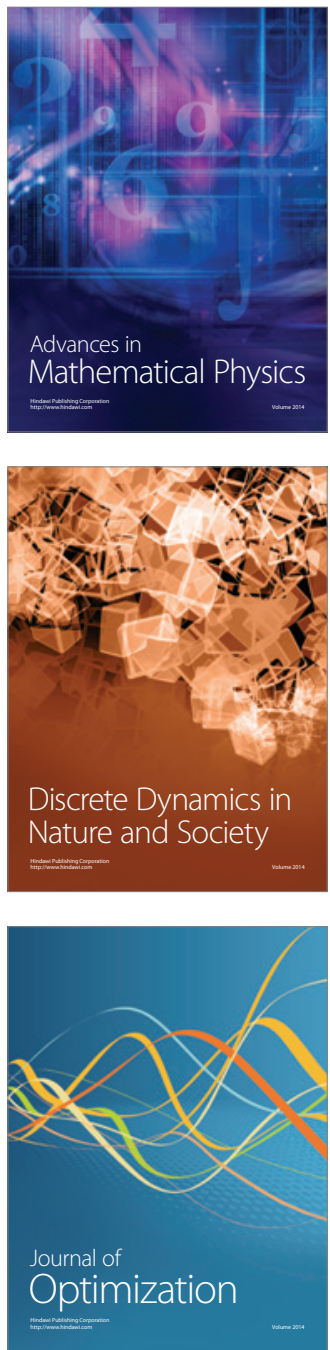